Supporting Information

For

\title{
In Vitro Systems Toxicology Assessment of a Candidate Modified Risk Tobacco Product Shows Reduced Toxicity Compared to a Reduced Cigarette
}

by

Ignacio Gonzalez-Suarez*, Florian Martin, Diego Marescotti, Emmanuel Guedj, Stefano Acali, Stephanie Johne, Remi Dulize, Karine Baumer, Dariusz Peric, Didier Goedertier, Stefan Frentzel, Nikolai V. Ivanov, Carole Mathis, Julia Hoeng, Manuel C. Peitsch

Philip Morris International R\&D, Philip Morris Products S.A., Quai Jeanrenaud 5, 2000 Neuchâtel, Switzerland

${ }^{*}$ Corresponding author

Table S1. List of biological networks and sub-networks.

Table S2. Selected AE, TPM and GVP concentrations for 3R4F and THS 2.2 used for the exposure of NHBE cells to generate gene expression data.

Figure S1. Carbonyl levels in AE and GVP from THS 2.2 aerosol and 3R4F smoke.

Figure S2. Cell viability across fractions.

Figure S3. HCS results in NHBE cells exposed for 4 h or 24 h to AE from 3R4F smoke and THS 2.2 aerosol.

Figure S4. HCS results in NHBE cells exposed for 4 h or 24 h to TPM from 3R4F smoke and THS 2.2 aerosol.

Figure S5. HCS results in NHBE cells exposed for $4 \mathrm{~h}$ or $24 \mathrm{~h}$ to GVP from 3R4F smoke and THS 2.2 aerosol.

Figure S6. Cell cycle analysis results in NHBE cells exposed for $24 \mathrm{~h}$ to AE, TPM and GVP from 3R4F smoke and THS 2.2 aerosol.

Figure S7. Biological Impact Factor (BIF).

Figure S8. NPA heatmaps for NHBE cells exposed for $4 \mathrm{~h}$ to one common dose of 3R4F smoke and THS 2.2 aerosol fractions. 


\begin{tabular}{|c|c|}
\hline Networks & Subnetworks \\
\hline \multirow{13}{*}{$\begin{array}{c}\text { Cell } \\
\text { Proliferacion }\end{array}$} & Calcium \\
\hline & Cell cycle \\
\hline & Cell interaction \\
\hline & Clock \\
\hline & Epigenetics \\
\hline & Growth factor \\
\hline & Hedgehog \\
\hline & Jak Stat \\
\hline & Mapk \\
\hline & Notch \\
\hline & Nuclear receptors \\
\hline & PGE2 \\
\hline & Wnt \\
\hline \multirow{6}{*}{ Cell stress } & Drug metabolism response \\
\hline & Endoplasmic reticulum stress \\
\hline & Hypoxic stress \\
\hline & NFE2L2 signaling \\
\hline & Osmotic stress \\
\hline & Oxidative stress \\
\hline \multirow{7}{*}{ Apoptosis } & Caspase cascade \\
\hline & ER stress-induced apoptosis \\
\hline & MAPK signaling \\
\hline & NFkB signaling \\
\hline & PKC signaling \\
\hline & Prosurvival mitochondrial signaling \\
\hline & TNFR1F signaling \\
\hline \multirow{3}{*}{ Autophagy } & ATG induction of autophagy \\
\hline & mTOR signaling \\
\hline & Nutrient transporter signature \\
\hline \multirow{8}{*}{ DNA damage } & Components afecting TP53 activity \\
\hline & Components affecting TP63 activity \\
\hline & Components affecting TP73 activity \\
\hline & DNA damage to G1-S checkpoint \\
\hline & DNA damage to G2-M checkpoint \\
\hline & Double-strand break response \\
\hline & Inhibition of DNA repair \\
\hline & TP53 transcriptional signature \\
\hline \multirow{2}{*}{ Necroptosis } & Fas activation \\
\hline & Gene signature \\
\hline \multirow{6}{*}{ Senescence } & Oncogene-induced senescence \\
\hline & Regulation by tumor suppressors \\
\hline & Regulation of p16INK expression \\
\hline & Replicative senescence \\
\hline & Stress-induced premature senescence \\
\hline & Transcriptional regulation of the SASP \\
\hline \multirow{4}{*}{ Inflammation } & Epithelial barrier defense \\
\hline & Epithelial proinflammatory signaling \\
\hline & Mucus hypersecretion \\
\hline & Tissue damage \\
\hline
\end{tabular}


Table S2

\begin{tabular}{|c|c|c|c|c|c|c|c|}
\hline & & \multicolumn{6}{|c|}{ CONCENTRATION (puff / I) } \\
\hline \multirow{2}{*}{$\mathrm{AE}$} & 3R4F & & $100 *$ & & & 25 & 13 \\
\hline & THS2.2 & 350 & 100 & & & 25 & \\
\hline \multirow{2}{*}{ GVP } & 3R4F & & $100 *$ & & & 25 & 13 \\
\hline & THS2.2 & 350 & 100 & & & 25 & 13 \\
\hline \multirow{2}{*}{ TPM } & 3R4F & & & & $32 *$ & 25 & 13 \\
\hline & THS2.2 & & & 38 & 32 & 25 & \\
\hline
\end{tabular}

Table S2. Selected AE, TPM and GVP concentrations for 3R4F and THS 2.2 used for the exposure of $\mathrm{NHBE}$ cells to generate gene expression data 
Figure S1
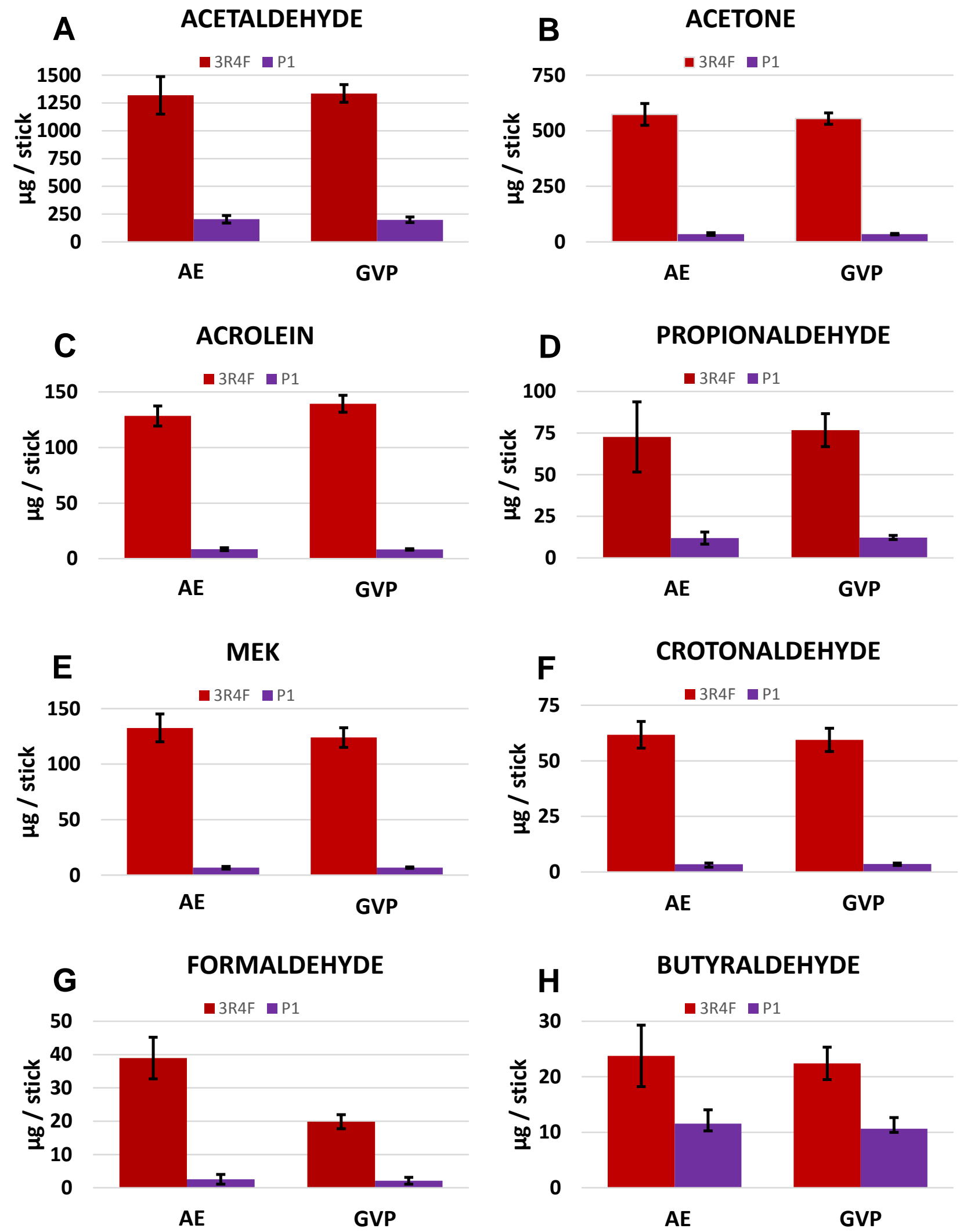

Figure S1. Carbonyl levels in AE and GVP from THS 2.2 aerosol and 3R4F smoke: A, Acetaldehyde; B, Acetone; C, Acrolein; D, Propionaldehyde; E, MEK; F, Crotonaldehyde; G, Formaldehyde; H, Butyraldehyde. Values are expressed as $\mu \mathrm{g}$ of carbonyl per one 3R4F cigarette or THS 2.2 stick and represent average and SEM from eight determinations performed on eight different smoke/aerosol generations on eight different days. * indicates $\mathrm{p}<0.0001$ vs. 3R4F (reference cigarette) by the paired t-test. 
Figure S2
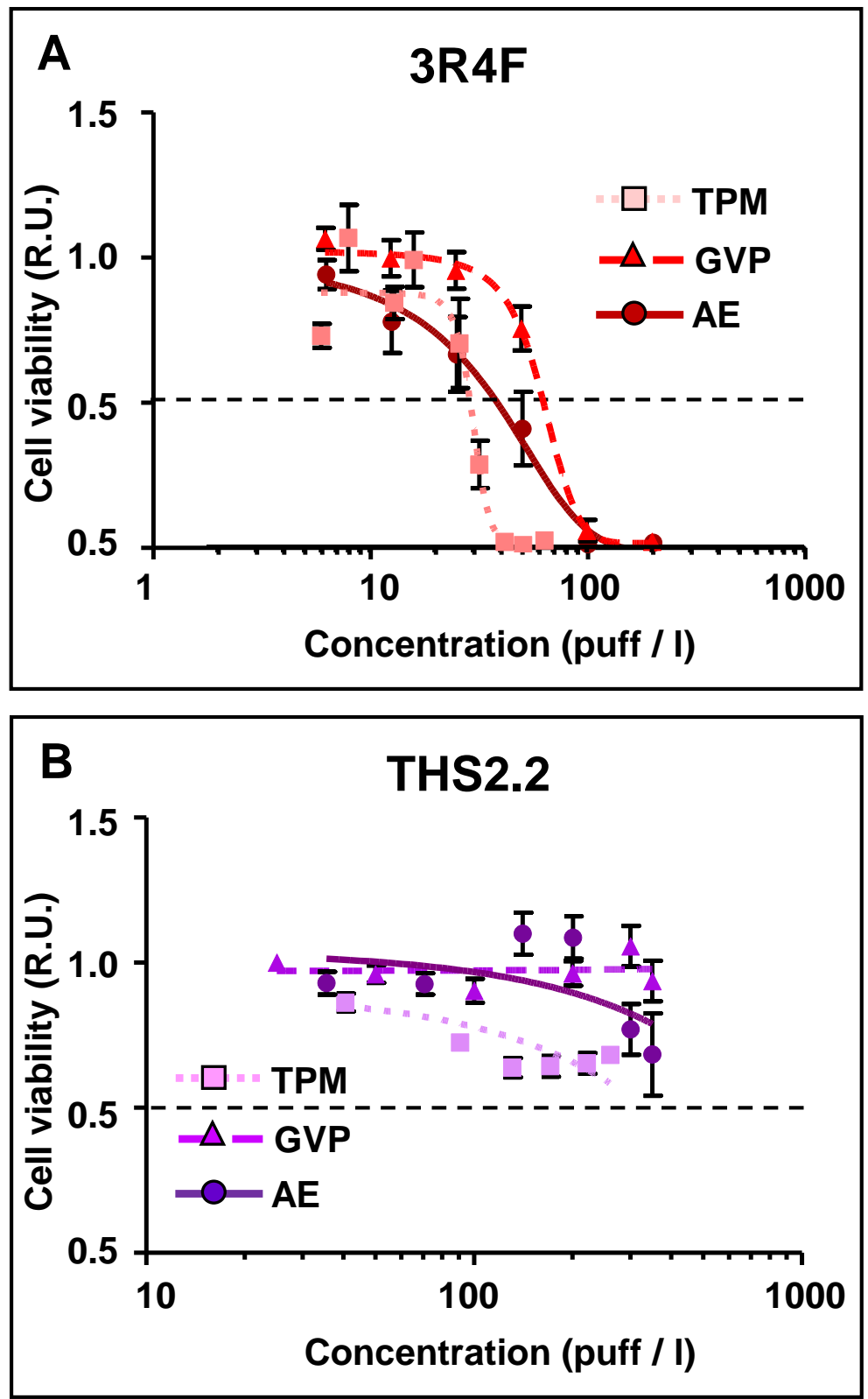

Figure S2. Cell viability across fractions. NHBE cells were exposed for 24h to AE, TPM or GVP fractions from (A) 3R4F smoke or (B) THS 2.2 aerosol and cell viability was measured using a real-time cellular analysis system. Values represent average \pm SEM of at least three independent experiments. Values are normalized to vehicle control. R.U. relative units. 

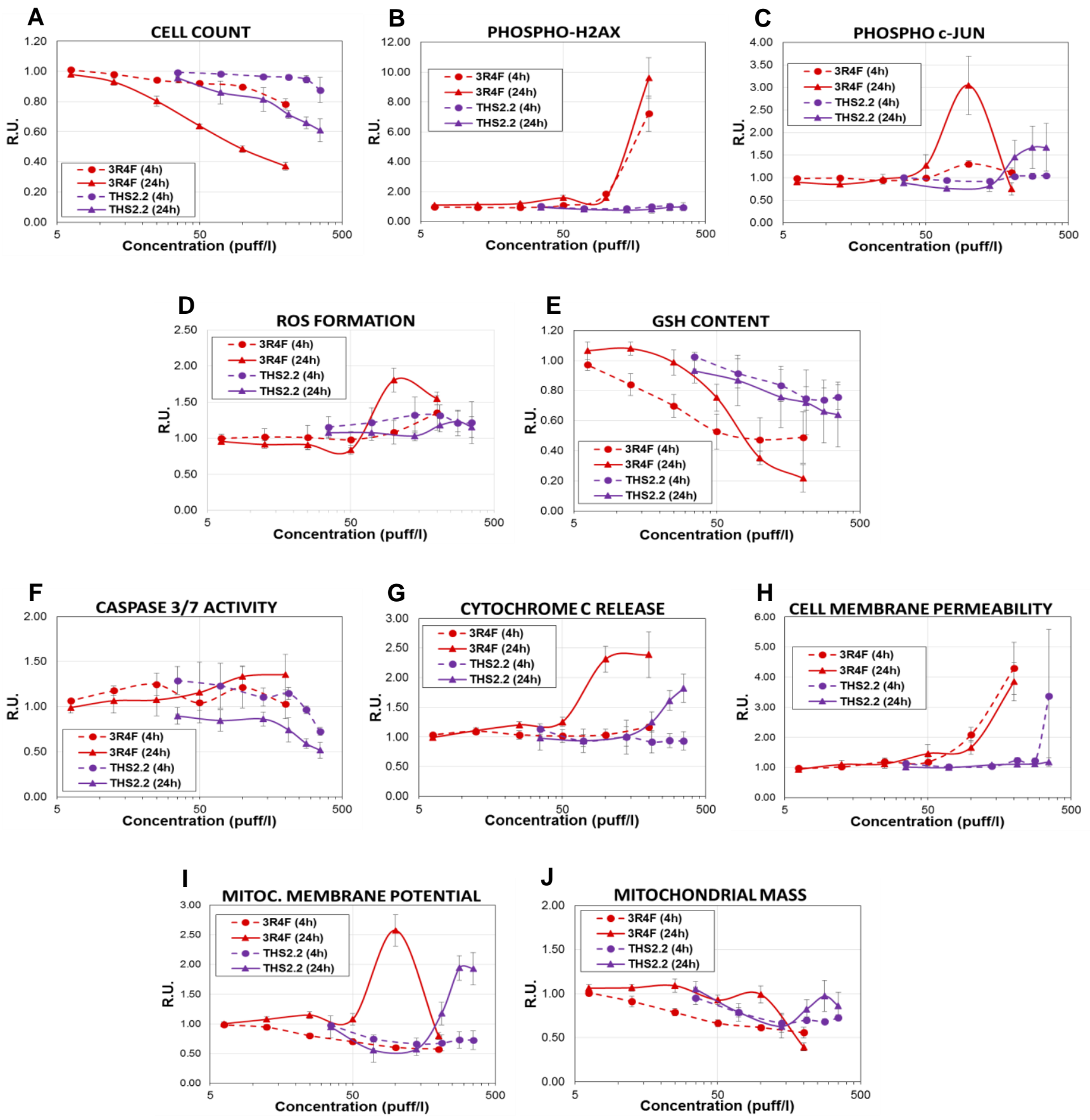

Figure S3. HCS results in NHBE cells exposed for $4 \mathrm{~h}$ or $24 \mathrm{~h}$ to AE from 3R4F smoke and THS 2.2 aerosol. Values were normalized to the vehicle control and represent average \pm SEM of at least three independent experiments $(n \geqslant 3)$ with independent smoke/aerosol generations on different days. The error bars represent SEM. * Significant different from the vehicle control. 

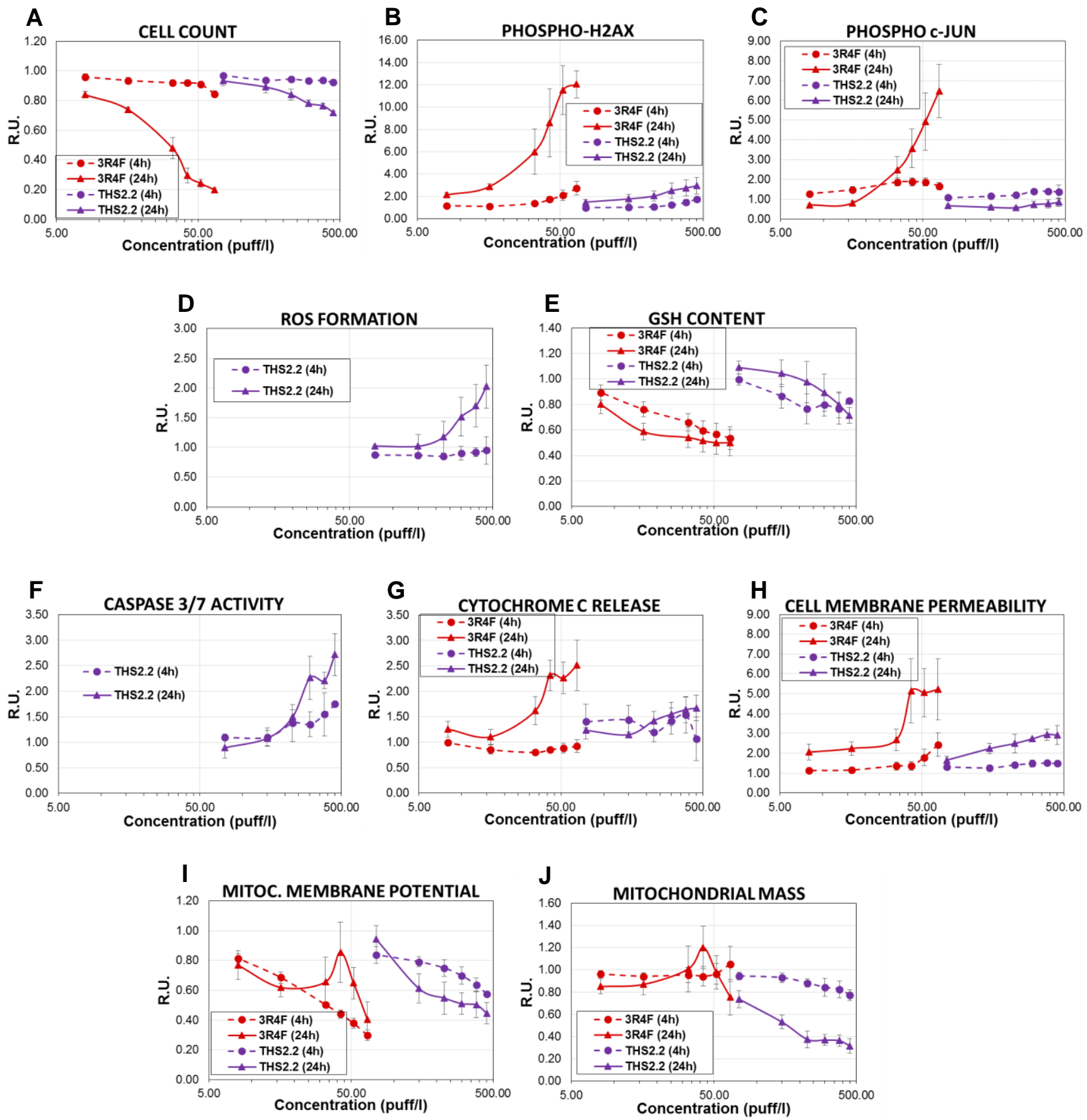

Figure S4. HCS results in NHBE cells exposed for 4h or 24h to TPM from 3R4F smoke and THS 2.2 aerosol. Values were normalized to the vehicle control and represent average \pm SEM of at least three independent experiments $(n \geqslant 3)$ with independent smoke/aerosol generations on different days. The error bars represent SEM. * Significant different from the vehicle control. 
A

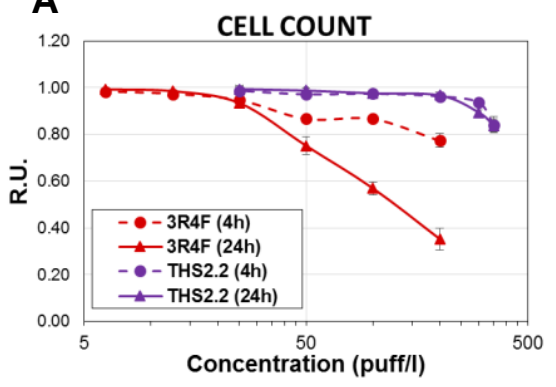

B

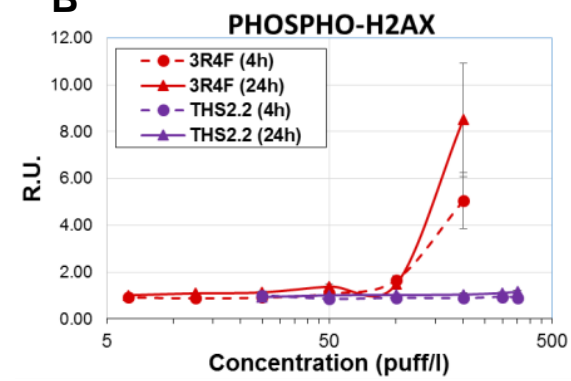

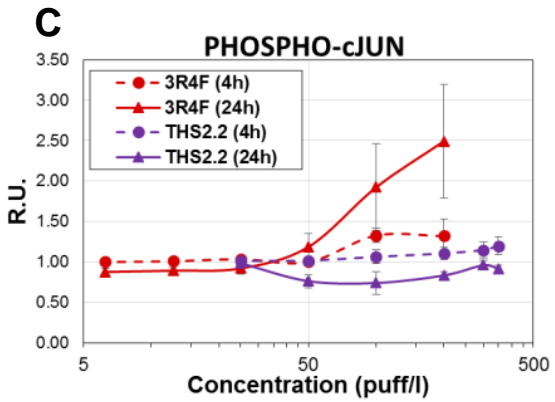
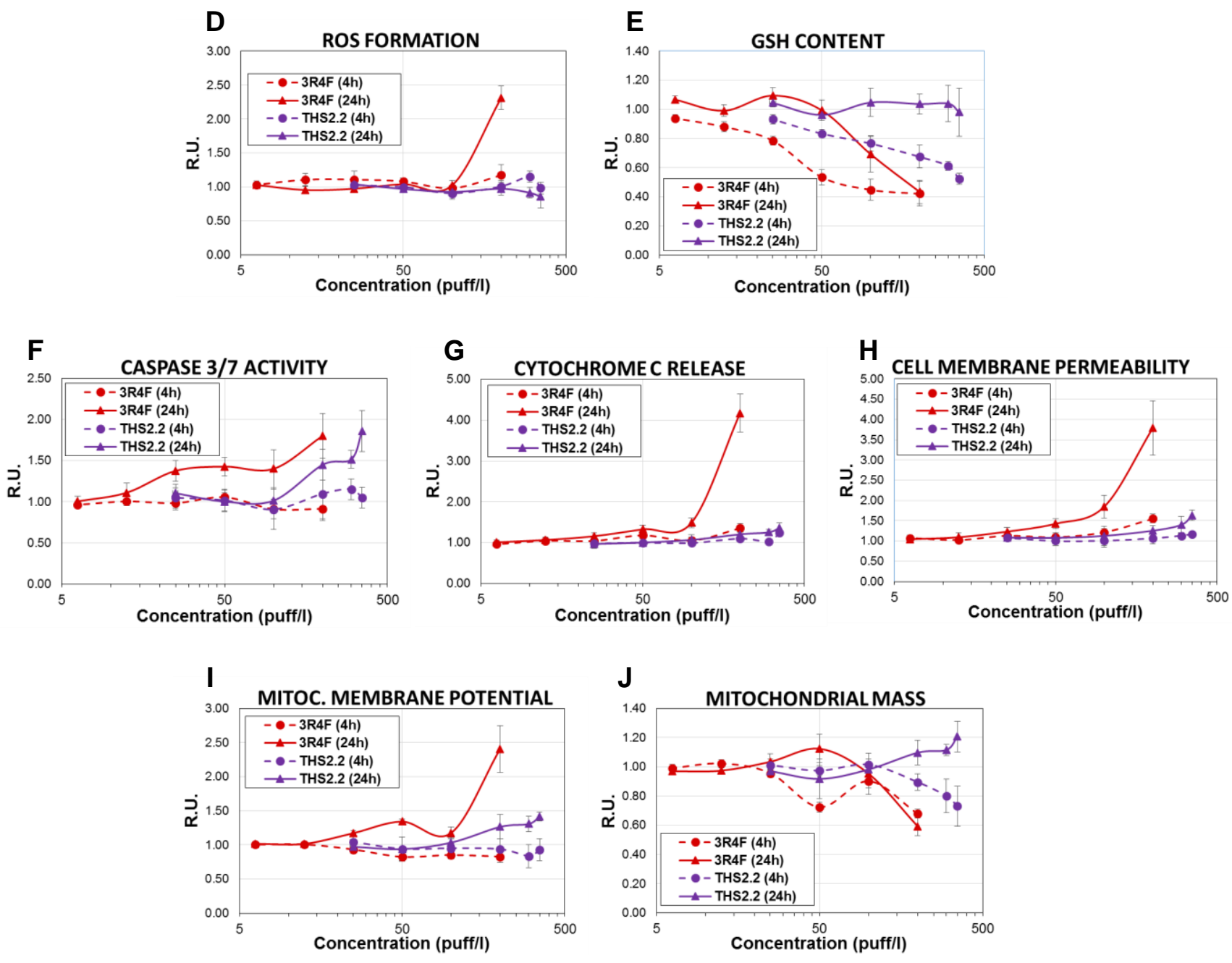

Figure S5. HCS results in NHBE cells exposed for $4 \mathrm{~h}$ or 24h to GVP from 3R4F smoke and THS 2.2 aerosol. Values were normalized to the vehicle control and represent average \pm SEM of at least three independent experiments $(n \geqslant 3)$ with independent smoke/aerosol generations on different days. The error bars represent the SEM. * Significant different from the vehicle control. 
A

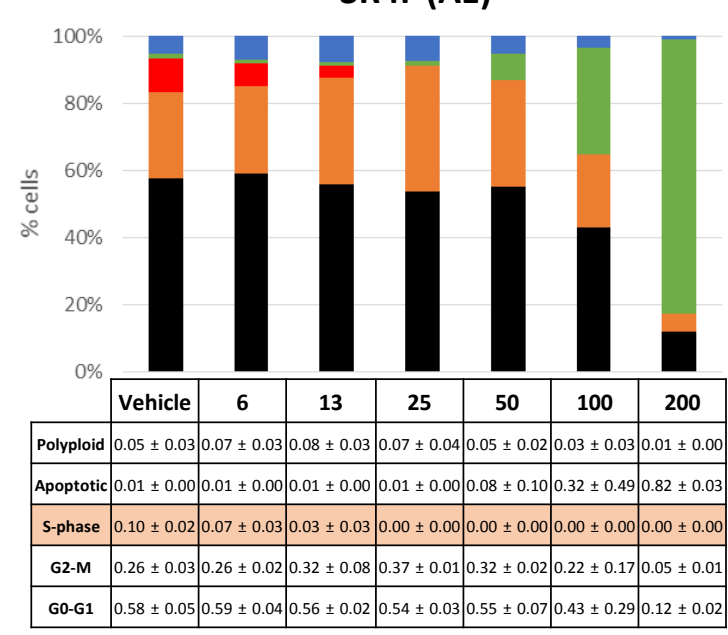

B

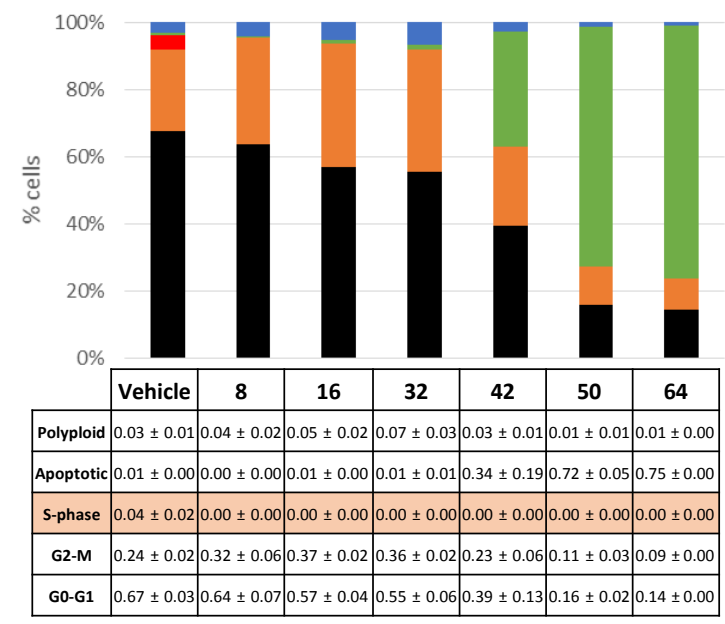

C

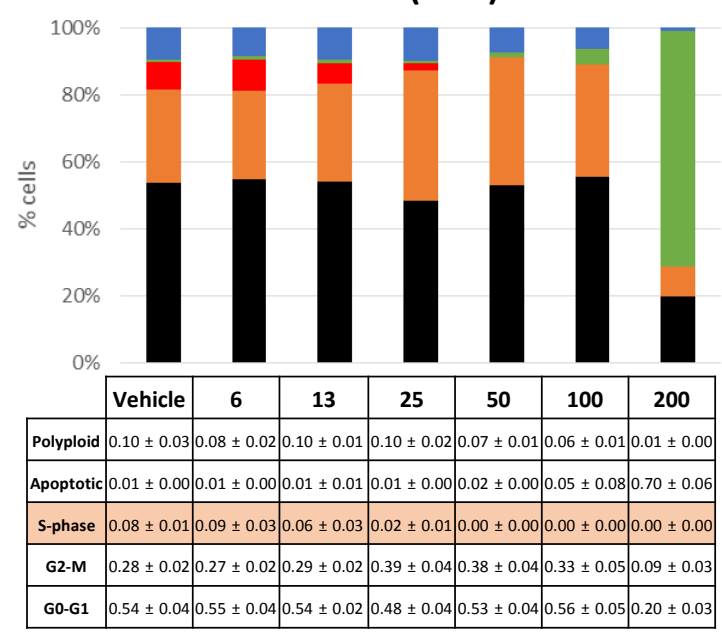

THS 2.2 (AE)

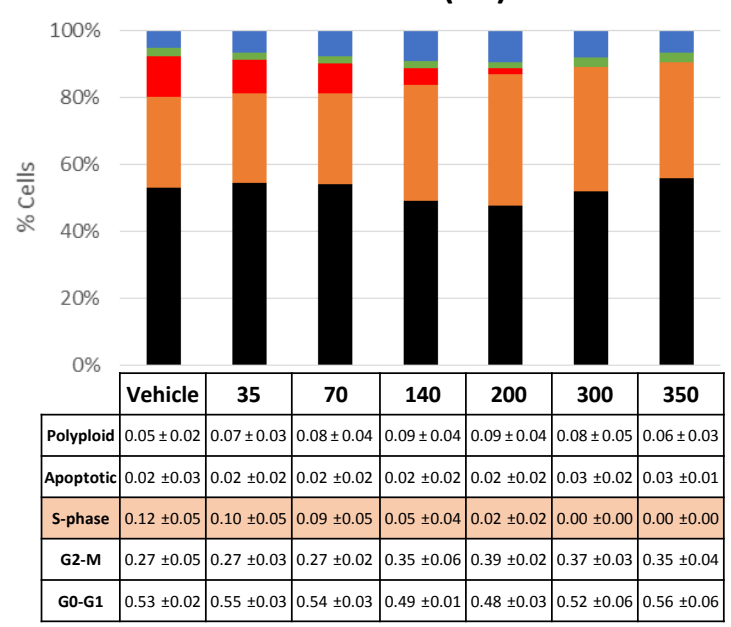

THS 2.2 (TPM)

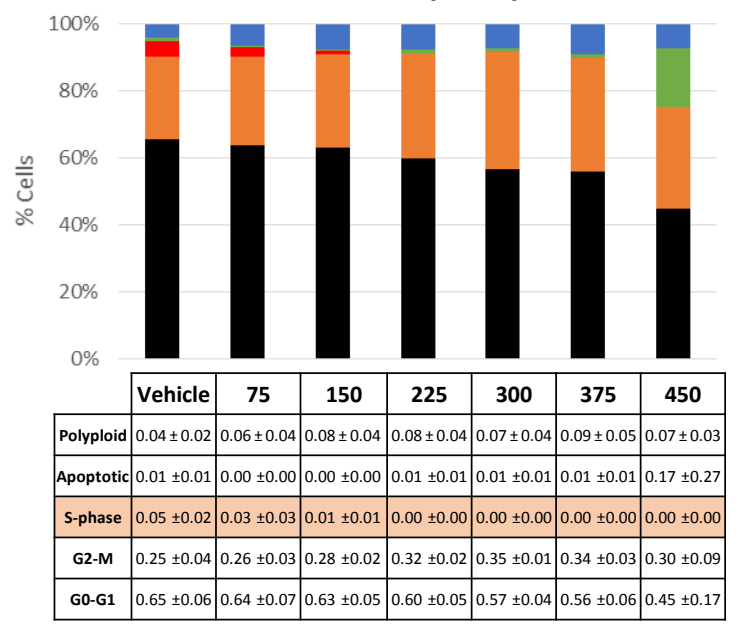

THS 2.2 (GVP)

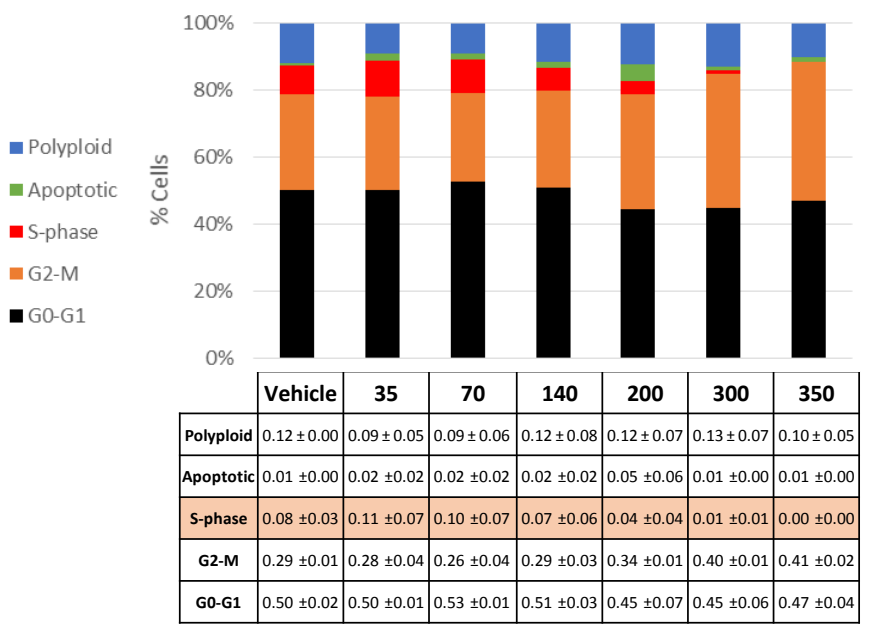

Figure S6. Cell cycle analysis results in NHBE cells exposed for $24 \mathrm{~h}$ to AE (A), TPM (B) and GVP (C) from 3R4F smoke and THS 2.2 aerosol. Values are expressed as cell percentage and represent the average of three independent experiments with independent smoke/aerosol generations on different days. Specific values of percentage of cells in different phases (polyploid, apoptotic, S-phase, G2-M, G0-G1) for each fraction concentration (indicated in bold in puffs/L), are expressed as average \pm standard deviation in the table below each graph. The percentage of cells in S-phase is highlighted in orange. 


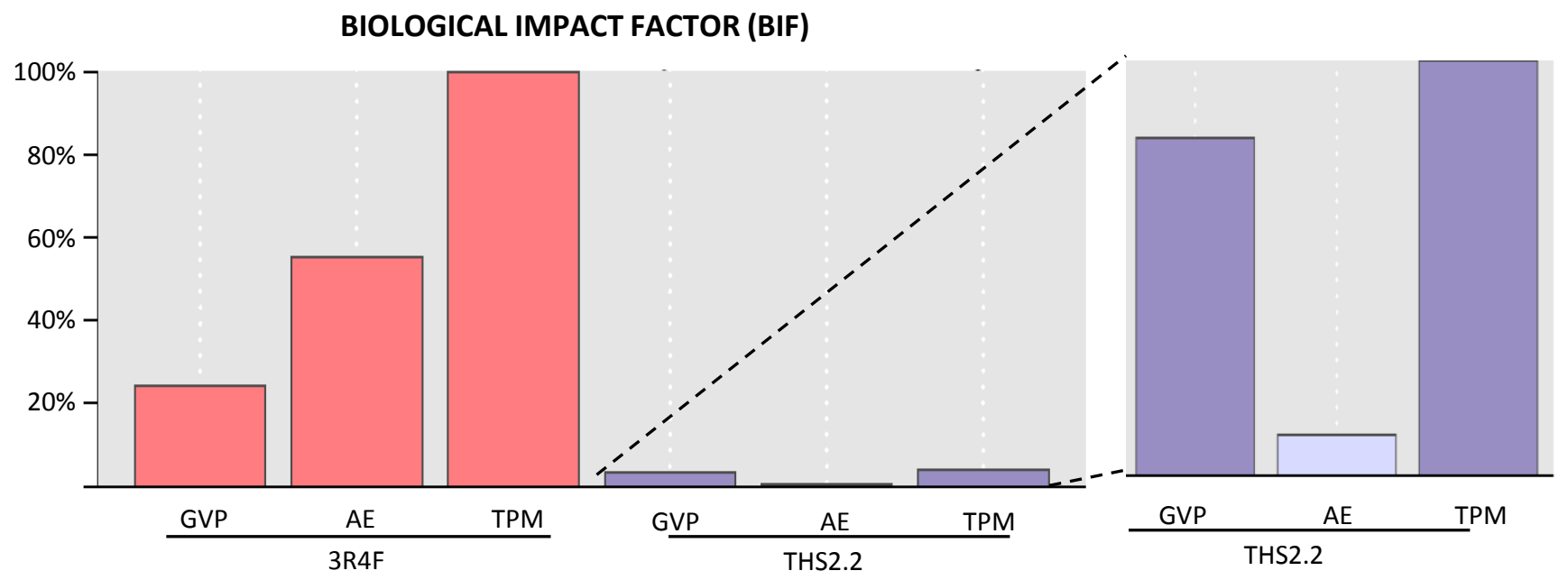

Figure S7. Biological Impact Factor (BIF). Relative BIF values for 3R4F and THS2.2 fractions at one common dose $(25 \mathrm{puff} / \mathrm{L})$. The percentages give the relative biological impact that is derived from the cumulated network perturbations caused by the treatment relative to the reference (3R4F TPM), which is defined as the treatment comparison showing the highest level of perturbation. 
Figure S8

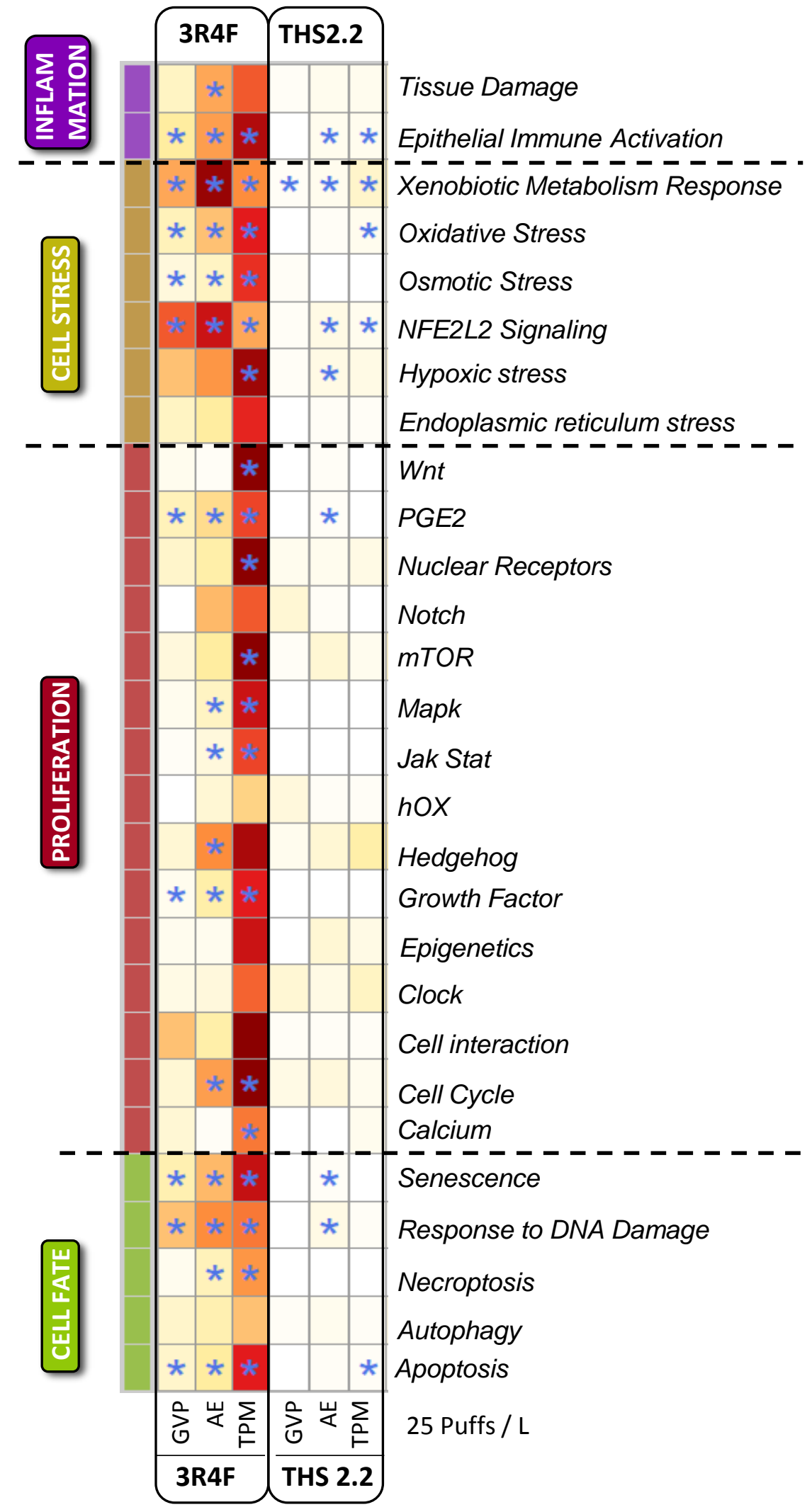

Figure S8. NPA heatmaps for NHBE cells exposed for $4 \mathrm{~h}$ to one common dose of 3R4F smoke and THS 2.2 aerosol fractions. Significantly perturbed networks are indicated as *. Darker colors indicate higher NPA scores. 